\title{
ÁREA DE RECEPÇÃO E LIMPEZA DO CENTRO DE MATERIAL E ESTERILIZAÇÃO: MANUTENÇÃO DO USO (OU NÃO) DE RESPIRADOR PARTICULADO POR TRABALHADORES APÓS A PANDEMIA DA COVID-19
}

DOI: 10.5327/Z1414-4425202000020001

D esde o fim de 2019, o mundo vem sendo desafiado pelo que se tornaria uma pandemia de infecção respiratória aguda, esta denominada de coronavirus disease 2019 (COVID19), diagnosticada pela primeira vez na China e causada pelo novo coronavírus humano ${ }^{1}$. Trata-se de um vírus de ácido ribonucleico, de fita simples, que mede de 60 a $140 \mathrm{~nm}(0,06-$ $0,14 \mu \mathrm{m}$ ) de diâmetro, com período de incubação entre três e sete dias, podendo alcançar até duas semanas ${ }^{2}$. Sua transmissão ocorre, primariamente, por via respiratória, por meio de gotículas ( $>5-10 \mu \mathrm{m}$ de diâmetro) ou contato direto com pessoa colonizada/infectada ou, indiretamente, por meio do contato com superfícies e/ ou objetos contaminados. Portanto, precauções-padrão e as baseadas na forma de transmissão, gotículas e contato, são recomendadas durante a assistência a pacientes com suspeita ou confirmação da infecção. Adicionalmente, em situações em que há geração de aerossóis ( $<5 \mu \mathrm{m}$ de diâmetro), a exemplo da aspiração endotraqueal, recomenda-se a adoção de precaução por aerossóis, que inclui o uso de respirador particulado descartável (máscara N95, PFF2 ou PFF3) 3.5. $^{3-5}$.

Diante desse novo cenário de pandemia, mudanças de comportamento das populações e, particularmente, das práticas em saúde tornaram-se necessárias e vêm sendo ajustadas à medida que evidências sobre o enfrentamento desse novo agente infeccioso são publicadas. Nesse sentido, a Associação Brasileira de Enfermeiros de Centro Cirúrgico, Recuperação Anestésica e Centro de Material e Esterilização publicou recomendações para equipes que trabalham em centro cirúrgico, centro de material e esterilização (CME) e serviços de endoscopia, visando às especificidades no atendimento a pacientes com suspeita ou confirmação de COVID-19, incluindo as relacionadas ao processamento de produtos para saúde (PPS). Entre as diretrizes, encontra-se o uso de respirador particulado, máscara N95, por trabalhadores para a limpeza manual de PPS, visto o potencial para formação de aerossóis durante esse processo ${ }^{6}$.

Sabe-se que, apesar da recomendação de limpeza automatizada como preferencial para o processamento de PPS, CME com disponibilidade de estrutura que permite apenas a limpeza manual desses produtos são uma realidade, sobretudo em países de baixa e média renda, o que inclui o Brasil ${ }^{7}$. Mesmo para serviços que dispõem de equipamentos para limpeza automatizada, a atual legislação brasileira para processamento de PPS, a Resolução da Diretoria Colegiada ${ }^{\circ}$ 15, de 2012, exige a realização de limpeza manual precedendo a automatizada para produtos de conformação complexa ${ }^{8}$. Adicionalmente, há evidências da geração de aerossóis na utilização de equipamentos para limpeza automatizada de PPS em CME, como lavadoras ultrassônicas?.

A legislação vigente para o processamento de PPS no país ${ }^{8}$, ao tratar "Da Segurança e Saúde no Trabalho", não especifica o uso da máscara N95 na área de recepção e limpeza de PPS. Todavia, ela assegura no artigo 31, parágrafo $3^{\circ}$, que "quando não especificado, o equipamento de proteção deve ser compatível com o risco inerente à atividade" "Já a publicação do Ministério da Saúde, de abril de 2020, sobre "Recomendações de proteção aos trabalhadores dos serviços de saúde no atendimento de COVID-19 e outras sindromes gripais" (grifo nosso) indica o uso de respiradores particulados para procedimentos geradores de aerossóis e reforça a necessidade do uso de equipamentos de proteção individual (EPI) "compatíveis com o risco inerente à atividade"4.

Assim, posto que as atividades realizadas na área de recepção e limpeza de CME geram aerossóis e que, no cotidiano laboral, os trabalhadores dessa área desconhecem o diagnóstico dos usuários dos PPS a serem processados, além da dificuldade imposta pelo atual cenário pandêmico em estimar o momento seguro para o retorno do uso das máscaras cirúrgicas — ou se é seguro — , consideramos oportuna a reflexão entre os trabalhadores e gestores de CME sobre a manutenção (ou não) do uso de respirador particulado, como a máscara N95, por trabalhadores que atuam na área de recepção e limpeza.

A permanência do uso desse EPI, consequentemente, incorrerá em custos adicionais ao sistema de saúde. Entretanto, esses custos ainda não foram estimados, assim como os gastos diretos e indiretos do tratamento de um trabalhador que desenvolva uma 
infecção respiratória decorrente de exposição laboral durante a limpeza de PPS. Independentemente dessa relação, vale destacar que a promoção e a proteção da saúde dos trabalhadores são responsabilidade do Sistema Único de Saúde e dever do Estado ${ }^{10}$.

Outrossim, é notório que o momento pandêmico explicitou inúmeras lacunas relacionadas à proteção dos trabalhadores da área da saúde que devem integrar as agendas de estudos e pesquisas dos enfermeiros, visto que lideram a maior equipe na área da saúde. Ademais, evidências científicas são necessárias para pautar a implementação de medidas que minimizem os riscos ocupacionais. Vale, ainda, ressaltar que, no Brasil, os profissionais dessa equipe são historicamente os envolvidos no gerenciamento e na execução do processamento de $\mathrm{PPS}^{11}$.
Anaclara Ferreira Veiga Tipple (i)

Doutora em Enfermagem pela Universidade de São Paulo (USP), Ribeirão Preto, Brasil. Professora titular da Faculdade de Enfermagem da Universidade Federal de Goiás (UFG), Goiânia,

Brasil. Coordenadora do Núcleo de Estudos e Pesquisa de Enfermagem em Prevenção e Controle de Infecções Relacionadas à Assistência à Saúde, Goiânia, Brasil.

Dayane de Melo Costa $($ ) Doutora em Enfermagem e em Ciências Biomédicas pela Universidade Federal de Goiás (UFG), Goiânia, Brasil, e pela Macquarie University (MQU), Sydney, Austrália. Pós-doutoranda do Programa de PósGraduação em Enfermagem da UFG, Goiânia, Brasil.

\section{REFERÊNCIAS}

1. World Health Organization. Statement on the second meeting of the International Health Regulations (2005) Emergency Committee regarding the outbreak of novel coronavirus (2019nCoV) [Internet]. World Health Organization; 2020 [acessado em $1{ }^{\circ} \mathrm{abr}$. 2020]. Disponível em: https://www.who.int/news-room/detail/30-01-2020-statementon-the-second-meeting-of-the-international-health-regulations(2005)-emergency-committee-regarding-the-outbreak-of-novelcoronavirus-(2019-ncov)

2. Cascella M, Rajnik M, Cuomo A, Dulebohn SC, Di Napoli R. Features, evaluation and treatment coronavirus (COVID-19). NCBI Bookshelf [Internet]. Treasure Island, FL: Stat Pearls Publishing; 2020 [acessado em 10 abr. 2020]. Disponível em: https://www.ncbi.nlm.nih.gov/books/ NBK554776/

3. Brasil. Ministério da Saúde. Agência Nacional de Vigilância Sanitária. Nota Técnica GVIMS/GGTES/ANVISA nº 04/2020. Orientações para serviços de saúde: medidas de prevenção e controle que devem ser adotadas durante a assistência aos casos suspeitos ou confirmados de infecção pelo novo coronavírus (SARS-CoV-2) (atualizada em 31/03/2020) [Internet]. Brasília: Ministério da Saúde; 2020 [acessado em $1{ }^{\circ}$ abr. 2020]. Disponível em: http://portal.anvisa.gov.br/documents/33852/271858/ Nota+T\%C3\%A9cnica+n+04-2020+GVIMS-GGTES-ANVISA/ ab598660-3de4-4f14-8e6f-b9341c196b28

4. Brasil. Ministério da Saúde. Agência Nacional de Vigilância Sanitária (ANVISA). COE/SVS/MS. Recomendações de proteção aos trabalhadores dos serviços de saúde no atendimento de COVID-19 e outras síndromes gripais [Internet]. Brasília: Ministério da Saúde, 2020 [acessado em $1^{\circ}$ abr. 2020]. Disponível em: https://portalarquivos.saude.gov.br/ images/pdf/2020/April/16/01-recomendacoes-de-protecao.pdf

5. World Health Organization. Modes of transmission of virus causing COVID-19: implications for IPC precaution recommendations [Internet]. World Health Organization; 2020 [acessado em $1{ }^{\circ}$ abr. 2020]. Disponível em: https://www.who.int/news-room/commentaries/detail/modesof-transmission-of-virus-causing-covid-19-implications-for-ipcprecaution-recommendations
6. Associação Brasileira de Enfermeiros em Centro Cirúrgico, Recuperação Anestésica e Centro de Material e Esterilização (SOBECC). Recomendações relacionadas ao fluxo de atendimento para pacientes com suspeita ou infecção confirmada pelo COVID-19 em procedimentos cirúrgicos ou endoscópicos [Internet]. SOBECC; 2020 [acessado em $1^{\circ}$ abr. 2020]. Disponível em: http://sobecc.org.br/arquivos/ RECOMENDACOES_COVID_-19_SOBECC_MARCO_20201.pdf

7. Mendonça ACC, Bezerra ALQ, Tipple AFV, Tobias GC. Quality indicators of health product processing in steam autoclaves. J Nurs UFPE. 2017;11(2):906-14. https://doi. org/10.5205/1981-8963-v1 1i2a13459p906-914-2017

8. Brasil. Ministério da Saúde. Agência Nacional de Vigilância Sanitária (ANVISA). RDC n 15, março de 2012. Dispõe sobre requisitos de boas práticas para o processamento de produtos para saúde [Internet]. Brasília: Ministério da Saúde; 2012. [acessado em $1{ }^{\circ}$ abr. 2020]. Disponível em: https://bvsms.saude.gov.br/bvs/saudelegis/ anvisa/2012/rdc0015_15_03_2012.html

9. Silva CLC, Hansen LL, Almeida AGCS, Kawagoe JY, Padoveze MC, Graziano KU. Negative pressure of the environmental air in the cleaning area of the materials and sterilization center: a systematic review. Rev Latino-Am Enferm. 2016; 24:e2781. https:// doi.org/10.1590/1518-8345.1140.2781

10. Brasil. Ministério da Saúde. Lei n 8.080, de 19 de setembro de 1990. Dispõe sobre as condições para a promoção, proteção e recuperação da saúde, a organização e o funcionamento dos serviços correspondentes e dá outras providências [Internet]. Brasília: Ministério da Saúde; 1990 [acessado em $1^{\circ} \mathrm{abr}$. 2020]. Disponivel em: http://www.planalto.gov. br/ccivil_03/leis/l8080.htm

11. Conselho Federal de Enfermagem (COFEn). Resolução Cofen $n^{\circ}$ 424/2012. Normatiza as atribuições dos profissionais de enfermagem em Centro de Material e Esterilização e em empresas processadoras de produtos para a saúde [Internet]. COFEn, 19 abr. 2012 [acessado em $1 \circ$ abr. 2020]. Disponível em: http://www.cofen.gov.br/resoluocofen-n-4242012_8990.html 